\title{
VARIA
}

\section{UNA ESCENA DEL QUIJOTE BORDADA POR ANTONIO GÓMEZ DE LOS RÍOS PARA EL DORMITORIO DE CARLOS III EN EL PALACIO REAL DE ARANJUEZ}

Durante los trabajos de inventario que se están efectuando en los almacenes del Oficio de Tapicería del Palacio Real de Madrid, se ha recuperado un bordado que representa una «Escena del Quijote» realizada al matiz y enmarcada por decoración vegetal, también bordada, pero a punto de cordoncillo, sobre un tafetán de seda moaré de color amarillo '.

Tanto por sus dimensiones como por su estilo y calidad, es preciso relacionar esta pieza con los veinticuatro cuadros bordados que con escenas del Quijote realizó el Bordador de Cámara Antonio Gómez de los Ríos, entre 1738 y 1741, para el entonces Príncipe de Asturias, D. Fernando, futuro Fernando VI y que, según palabras del propio artífice, «merecieron la Real aprobación» ${ }^{2}$.

Estas veinticuatro escenas adornaron, en el siglo xIX, el sevillano Palacio de San Telmo de los Duques de Montpensier ${ }^{3}$, a cuyas manos habían llegado por herencia. La belleza y lo curioso de estos bordados causaron impresión en algún cronista de la época, reseñándolos entre las obras más destacadas de aquella colección: «Los que no hayan visitado el palacio de San Telmo no pueden formarse una idea, por mucho que digamos, del buen gusto y de la magnificencia que allí reinaba ... Mosaicos de gran precio, cuadros realizados con raro acierto del

${ }^{1} \mathrm{El} \mathrm{n}{ }^{\circ}$ de inv $v^{\circ}$ de la pieza es 10175558 . Quiero destacar aquí el excelente trabajo de inventario y clasificación que están realizando los dos equipos de inventario que actualmente están trabajando en el Almacén de Telas del Oficio de Tapicería del Palacio Real de Madrid.

2 Memorial del bordador elevado al rey en 1748, pidiendo una ración ordinaria para mantener a sus ocho hijos, conservado en Archivo General de Palacio, expediente personal de Antonio Gómez de los Ríos, C ${ }^{a}$ 450/3. Sobre este bordador, consultar: J. Domínguez Bordona, «Noticia de un pontifical bordado para Fernando VI», A.E.A.A., t. X, 1934, pp. 269-271; F. Niño Mas, «Una obra del bordador de Cámara Antonio Gómez de los Rios, A.E.A., n 45, 1941, pp. 309-310 y los de M. L. Barreno Sevillano, «Bordadores de cámara y situación del arte de bordar en Madrid, durante la segunda mitad del siglo xviI», A.E.A., n ${ }^{\circ} 187,1974$, p. 274; «Pontifical Bordado», RR. SS., n 56, 1978, pp. 17-24 y «Doseles bordados para la Corona de España en el siglo XVIII (1)», RR. SS., nº 59,1979, p. 59.

3 «Paso de la saleta al comedor nuevo. $N^{\circ}$ 621:Veinte y cuatro cuadros bordados en seda de la vida del Quijote. Alto cada uno 2 pies, 1 pulgada, ancho 2 pies, 6 pulgadas» Catalogo de los cuadros y esculturas pertenecientes a la galería de SS.AA. Los Serenísimos Infantes de España Duques de Montpensier, Sevilla, 1866, p. 62. Doce de estos cuadros bordados salieron a subasta en Madrid, en 1966, (cfr. Gran colección de procedencia real. Subastas Fernando Durán, Madrid, 6 de junio de 1996, lote $n^{\circ}$ 197). El lote fue declarado inexportable por el Ministerio de Educación y Cultura a propuesta de la Dirección General de Bellas Artes y de Conservación y Restauración de Bienes Culturales, previo informe favorable de la Junta de Calificación, Valoración y Exportación de Bienes del Patrimonio Histórico Español, acordado en la sesión plenaria del día 3 de junio. Con posterioridad a la subasta, fue adquirido por un particular, ingresando con posterioridad en el Museo de Navarra ( $\mathrm{n}^{\circ}$ de registro: 3354, código del Inventario General de Bienes Muebles: IM060000404). 
manchego hidalgo, tibores ... pinturas al óleo de los más afamados artistas, todo esto en orden admirable...» ${ }^{4}$.

La autoría de la pieza conservada actualmente en el Palacio Real de Madrid se ve confirmada por la documentación que acredita la intervención de Antonio Gómez de los Ríos en la decoración del dormitorio de Carlos III en el Palacio Real de Aranjuez llevada a cabo en 1762; habitación para la cual el bordador realizó diferentes trabajos entre los que figuraron «la colgadura de moaré de aguas amarillo cortinas, taburetes, sillas, canapé y mampara de chimenea», pieza esta última descrita en la documentación como «de media vara de alto y tres cuartos de ancho $(41,8 \times 62,7 \mathrm{~cm})$ con once figuras manteando a Don Quijote, bordada de sedas flojas» ${ }^{5}$. Aunque en realidad, la escena no representa el manteo de don Quijote, sino, como es sabido, el manteo de Sancho, con todos los detalles narrados en el capítulo XVII de la obra de Cervantes:

«Quiso la mala suerte del desdichado Sancho, que entre la gente que estaba en la venta se hallasen cuatro perailes de Segovia, tres agujeros del Potro de Córdoba y dos vecinos de la heria de Sevilla, gente alegre, bien intencionada, maleante y juguetona, los cuales, casi como instigados y movidos por un mismo espíritu, se llegaron a Sancho, y apeándole del asno, uno dellos entró por la manta de la cama del huésped, y echándole en ella, alzaron los ojos y vieron que el techo era algo más bajo de lo que habían menester para su obra, y determinaron salirse al corral que tenía por límite el cielo, y allí puesto Sancho en mitad de la manta, comenzaron á levantarle en alto y a holgarse con él como con perro por carnestolendas. Las voces que el mísero manteado daba fueron tantas, que llegaron á los oídos de su amo, el cual deteniéndose á escuchar atentamente, creyó que alguna nueva aventura le venía, hasta que claramente conoció que el que gritaba era su escudero; y volviendo las riendas, con un penado galope llegó á la venta, y hallándola cerrada, la rodeó por ver si hallaba por dónde entrar; pero no hubo llegado á las paredes del corral, que no eran muy altas, cuando vió el mal juego que se le hacía á su escudero. Vióle bajar y subir por el aire con tanta gracia y presteza, que si la cólera le dejara, tengo para mí que se riera.»

Hasta el momento no he podido localizar la fuente en la que se basó Gómez de los Ríos para bordar todas estas escenas. Hay que tener en cuenta que las series iconográficas del Quijote de mayor importancia y difusión a lo largo del siglo xviII o bien fueron coetáneas al trabajo del bordador español, como las de Coypel y Vanderbank publicadas por primera vez en 1731 y 1738 respectivamente, o bien son posteriores, como la dirigida por la Real Academia Española de 1780 y en la que intervinieron los principales dibujantes y grabadores españoles de la época. Anteriores a estas publicaciones hubo pocas ediciones de la novela de Cervantes que contaran con un número elevado de láminas que fueran de utilidad al bordador; Únicamente las láminas de Jacobo Savry, publicadas en 1656 y reproducidas en varias ediciones posteriores como las de Bruselas de 1662, la de Amberes de 1673, la de Madrid de 1674 o la de Lyon de 1736 pudieron haber servido de inspiración a Gómez de los Ríos, pero su estilo y composición son mucho más arcaicos que los de los bordados.

Por otro lado, hay que recordar que para la realización de la que fue su obra más importante, el conjunto de ornamentos litúrgicos conocido como «Pontifical de Fernando VI», Gómez de los Ríos no se basó únicamente en repertorios de grabados sino también en pinturas, lo que podría inducir a pensar que hiciera lo mismo con sus escenas del Quijote; sin embargo, la

${ }^{4}$ F. M. Tubino, La corte en Sevilla, crónica del viaje de SS MM y AA a las provincias andaluzas en 1862, Sevilla, 1862, p. 315, transcrito por V. Lleó Cañal, La Sevilla de los Montpensier, segúnda corte de España, Sevilla, 1997, p. 103.

5 A.G.P., Sección Reinados, Carlos III, leg. 3762. Agradezco a mi amiga y compañera Ana García Sanz la documentación que me ha facilitado. 


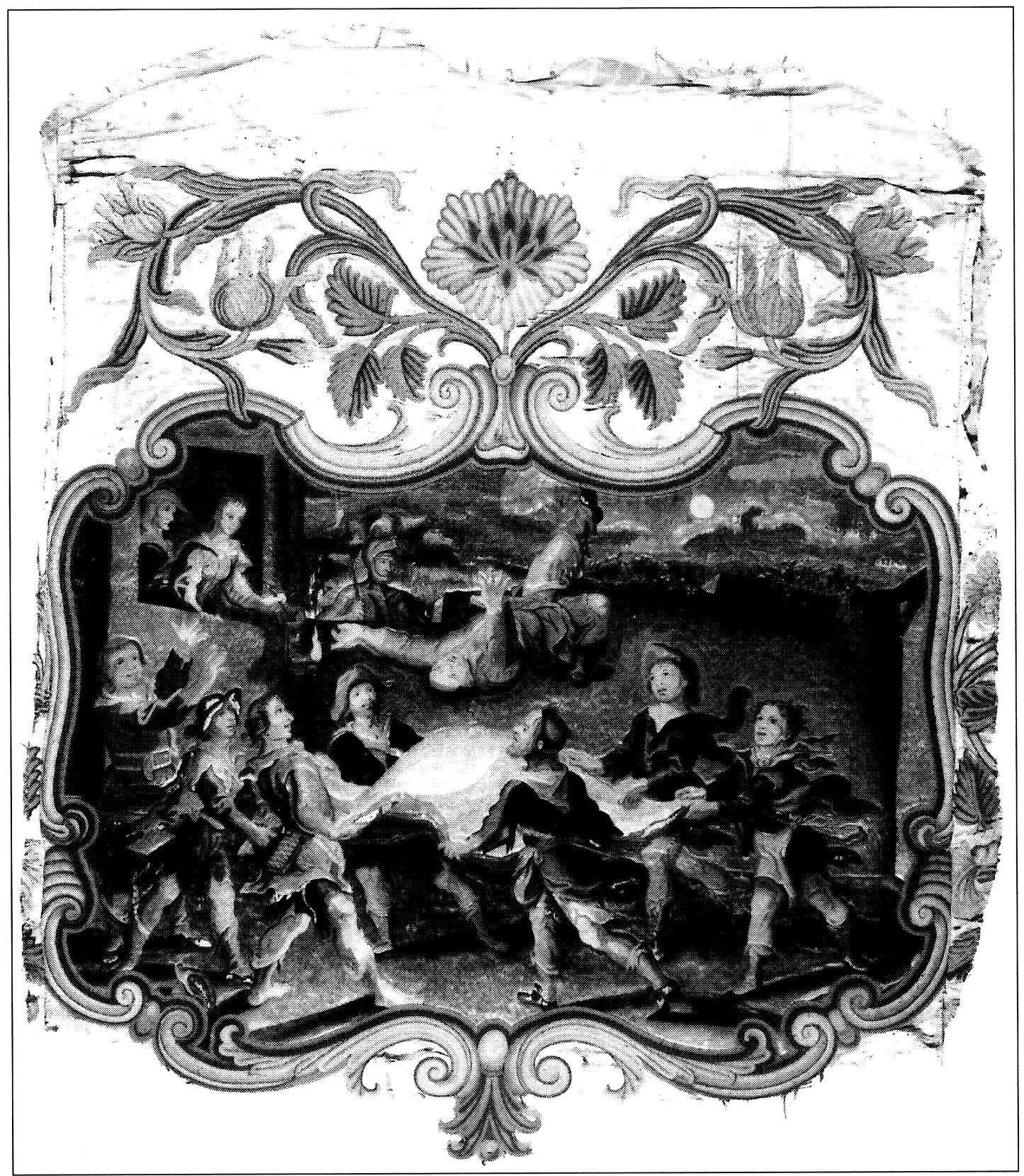

Fig. 1. A. Gómez de los Ríos: Una escena del Quijote bordada. Madrid, Palacio Real.

única serie pictórica del Quijote de importancia anterior a la fecha de sus bordados, fue la que hiciera Jean Monier en el Palacio de María de Médicis en Chaveny que tampoco tiene relación con lo representado por el bordador. Entre las pintadas en España, ni la del francés Miguel Angel Houasse, ni las de los italianos Andrea Procaccini y Domingo María Sani, tejidas posteriormente en tapiz, se corresponden con el trabajo de Gómez de los Ríos.

Cuando en 1762, Gómez de los Ríos acudió al Real Sitio de Aranjuez a «colgar la alcoba del Rey» ${ }^{6}$ habían pasado más de veinte años desde que entregara los veinticuatro cuadros del

${ }^{6}$ A.G.P., Reinados, Carlos III, leg. 3762. 
Quijote para el Gabinete del Príncipe de Asturias. ¿Retomó el artista el tema del Quijote para el adorno del dormitorio de Carlos III de Aranjuez?, ¿o aprovechó una escena que no había entregado a Fernando VI pero que ya tenía bordada?

Es fácil responder a esta cuestión si se comparan los bordados entre sí. El estilo de las figuras, la técnica y las medidas de las escenas coinciden en todos. La única diferencia notable radica en que las piezas que estuvieron colgadas en el Palacio de San Telmo de Sevilla se adornan perimetralmente por una cenefilla de haces de hojas, que en la zona inferior, forma una cartela en la que se señala la temática de la escena y el capítulo de la novela de Cervantes a que pertenece, todo igualmente bordado a matiz, mientras que la escena conservada en Madrid carece de estos adornos.

A pesar del encuadre ondulado que presenta este último bordado, si se observa por detrás, se puede apreciar que la escena es en realidad rectangular, que ha sido bordada sobre una gruesa arpillera y no sobre el moaré que le sirve de enmarque y que, en su zona inferior, queda un espacio libre de la arpillera sin bordar, que podría haberse usado para bordar la cartela. Así pues, el conjunto está compuesto por la unión de dos piezas diferentes, la «Escena del Quijote» y el encuadre bordado en moaré amarillo.

Todas estas circunstancias confirmarían que la «Escena del Quijote» era una obra originalmente destinada a formar parte del conjunto bordado para el Príncipe. Es posible que ésta escena hubiera sido una muestra que presentara para la aprobación general del conjunto o, más probablemente, que, fuera bordada en último lugar y al no estar concluida no fuera entregada, quedando en poder de su autor que tuvo oportunidad de utilizarla veinte años después, cuando se le encargó bordar la colgadura de la alcoba de Carlos III en el Palacio Real de Aranjuez, confeccionando con ella la pantalla de chimenea ${ }^{7}$.

Pilar Benito García

\section{UN ESCRITORIO FLORENTINO DE «PIEDRAS DURAS»EN LA COLEGIATA DE TORRIJOS (TOLEDO)}

Es conocida por su magnificencia la Colegiata de la villa toledana de Torrijos, comenzada al parecer en 1509 por los hermanos Egas y dedicada al «Corpus Christi» por su fundadora doña Teresa Enríquez, la «Loca del Sacramento», mujer del poderoso don Gutierre de Cárdenas 1.

Entre las numerosas obras de arte que allí aún se guardan nos llamó la atención el actual sagrario colocado delante del espléndido retablo mayor, tras la piedra del altar ${ }^{2}$. A simple vista detectamos que se trata de una pieza italiana de «Pietre Dure» que el Conde de Cedillo, que ya lo registra en su Catálogo de la Provincia de Toledo ${ }^{3}$, señala como dedicado antiguamente

\footnotetext{
${ }^{7}$ Está próximo a publicarse el estudio que, a raíz del hallazgo de este bordado inédito de Gómez de los Ríos, en 1998, estoy realizando sobre la decoración de esta estancia del Palacio Real de Aranjuez y sobre otras obras del genial bordador.

1 La bibliografía sobre doña Teresa Enríquez es muy numerosa; solamente citaremos la obra de Manuel Castro y Castro, Teresa Enríquez, la "Loca del Sacramento» y Gutierre de Cárdenas, Toledo, IPIET, 1992.

2 Isabel Mateo Gómez: «Nueva aportación documental a la obra de Juan Correa de Vivar: el retablo mayor de Santiago del Arrabal de Toledo y el de la iglesia parroquial de Torrijos (Toledo)», Archivo Español de Arte, n. ${ }^{\circ} 208,1979$, pp. 461472.

${ }^{3}$ Conde de Cedillo: Catálogo Monumental de la Provincia de Toledo, Diputación Provincial de Toledo, 1959 , p. 368.
} 